\title{
A temporal sediment record of microplastics in an urban lake, London, UK
}

\author{
Simon Turner (1) - Alice A. Horton (1) - Neil L. Rose 1 - Charlotte Hall
}

Received: 26 January 2018/ Accepted: 5 February 2019/Published online: 13 February 2019

(C) The Author(s) 2019

\begin{abstract}
A radionuclide-dated $\left({ }^{210} \mathrm{~Pb}\right.$ and $\left.{ }^{137} \mathrm{Cs}\right)$ sediment core collected from Hampstead Pond No. 1, a North London lake, was used to provide novel data on the historical accumulation of microplastic waste in the urban environment. Microplastics were extracted from sediments by sieving and dense-liquid separation. Fibres of anthropogenic origin dominated the assemblage. Microplastics were first identified by microscopy before Raman spectroscopy of selected particles was used to determine the composition of synthetic polymers and dyes. Polystyrene microplastic particles were identified, in addition to synthetic fibres of polyacrylonitrile, polyvinyl chloride and fibres containing synthetic dyes. Concentrations of total microplastics in the sediment samples ranged from detection level to 539 particles per kilogram of dried sediment. Proliferation of microplastics is evident in
\end{abstract}

Electronic supplementary material The online version of this article (https://doi.org/10.1007/s10933-019-00071-7) contains supplementary material, which is available to authorized users.

S. Turner $(\bowtie) \cdot$ N. L. Rose · C. Hall

Department of Geography, Environmental Change

Research Centre, University College London, Gower

Street, London WC1E 6BT, UK

e-mail: simon.turner@ucl.ac.uk

\section{A. A. Horton}

Centre for Ecology \& Hydrology, Maclean Building,

Benson Lane, Crowmarsh Gifford, Wallingford,

Oxfordshire OX10 8BB, UK the core from the late 1950 s to the present. Relatively low numbers of particles were found in older sediments, comparable to laboratory blanks, highlighting the difficulty of extending a plastic chronostratigraphy back to the early twentieth century. This study shows that, with optimisation, routine extraction of microplastics from radionuclide-dated lake sediments can add an important temporal perspective to our understanding of microplastics in aquatic systems.

Keywords Microplastics · Freshwater - Lead-210 . Sediment $\cdot$ Plastic pollution

\section{Introduction}

The accumulation of plastic waste in freshwater aquatic systems has become a relatively recent focus of research (Moore et al. 2011; Zbyszewski and Corcoran 2011; Wagner et al. 2014; Eerkes-Medrano et al. 2015), despite its high visibility, potential for association with other contaminants (Rochman et al. 2013) and known resistance to degradation. Microplastics (including synthetic fibres) $<5 \mathrm{~mm}$ in size are of interest due to the likelihood of ingestion by freshwater organisms and, because they have large specific surface area, their potential for adsorption and leaching of associated contaminants and additives (Lobelle and Cunliffe 2011; Sanchez et al. 2014; Faure 
et al. 2015; Näkki et al. 2017). Pellets and 'microbeads' specifically manufactured as microplastic forms (primary microplastics) may be found in freshwaters subject to large inputs of industrial drainage or effluent (Castañeda et al. 2014; Lechner et al. 2014; Corcoran et al. 2015; Driedger et al. 2015; Baldwin et al. 2016; Horton et al. 2017a; Horton and Dixon 2018), although secondary microplastics (derived from the breakdown of larger plastic items) dominate in freshwater sediments subject to more diffuse plastic waste sources (Free et al. 2014; Driedger et al. 2015; Faure et al. 2015; Zhang et al. 2016; Blettler et al. 2017; Matsuguma et al. 2017; Sruthy and Ramasamy 2017; Imhof et al. 2018).

In the absence of long-term monitoring of plastic waste (Barnes et al. 2009), analysis of environmental archives capable of capturing and accumulating plastic, should enable retrospective assessment of the occurrence, usage patterns and changing types of plastics through time. Plastics are highly persistent, with many estimated to take hundreds of years to degrade, and are therefore likely to accumulate in sediment deposits (Andrady 2003; Barnes et al. 2009). To understand previous and current amounts and varieties of plastics in the environment, a temporal perspective is invaluable. Unlike other global contaminants, however, plastic waste accumulation has not, until now, been analysed within the context of a well-constrained lake sediment sequence.

Lakes provide excellent depositional contexts for recording the transport of contaminants within and through catchments (Boyle 2001; Engstrom and Rose 2013). Especially valuable in the historical framework of plastic waste (Zalasiewicz et al. 2016) is the presence of well-defined, datable sediments over the last ca. 150 years that, compared to marine cores (Woodall et al. 2014; Martin et al. 2017), are more accessible and proximal to terrestrial sources of plastic contamination. Lakes therefore represent catchmentscale sinks for microplastic debris compared with oceans, which are subject to global-scale long-range transport from multiple catchments (Hidalgo-Ruz et al. 2012; Hardesty et al. 2017). The volume and composition of plastic waste found at one point in time and space in an aquatic system, will comprise a cumulative component, as a consequence of temporary storage and reworking in the catchment. Benthic sediment is an end member of microplastic transport in freshwater systems, but more research is required to quantify transport pathways, burial and biological interactions within lacustrine systems.

Microplastics have been found in lake sediments, with inputs linked to urbanization, industrial activities and wastewater influences (Castañeda et al. 2014; Corcoran et al. 2015; Driedger et al. 2015; Su et al. 2016; Blettler et al. 2017), but high-resolution sediment evidence of the historical incorporation of microplastics in lake sediments, indeed in any codated or cross-correlated aquatic/estuarine sediment, is surprisingly rare (Cundy et al. 1998; Corcoran et al. 2015; Matsuguma et al. 2017; Willis et al. 2017). Previous age/depth measurements of lake-sediment microplastic abundance were estimated either by comparison with historical trends of other contaminants or by correlation with other cores (Corcoran et al. 2015; Matsuguma et al. 2017). In freshwater environments, however, variations in sediment accumulation affect burial of microplastics, and so historical records must be reliably dated to quantify rates of incorporation in benthic sediments.

This study aimed to:

a. Obtain the first record of microplastics in lake sediment core samples dated with radionuclides $\left({ }^{210} \mathrm{~Pb},{ }^{137} \mathrm{Cs}\right)$ and co-measured with paleolimnological indicators of human activity.

b. Provide a first look at the changing composition and abundance of microplastic debris in lake sediments that span the twentieth century to present day.

c. Provide a straightforward method for separation of microplastics from lake sediment matrices that can be added to the paleolimnological toolset.

This paper provides a significant contribution to our knowledge of sources, transport pathways and fate of plastic debris in freshwater environments (Schmidt et al. 2017). The data are further evidence of the ubiquity of microplastics in global environments and contribute to the discussion on plastic waste as a stratigraphic marker for the Anthropocene (Zalasiewicz et al. 2016).

Study site

Hampstead No.1 Pond is a small water body (1.5 ha, max $3 \mathrm{~m}$ depth) in North London, United Kingdom (Lat $51.5575^{\circ}$, Long $-0.1655^{\circ}$, $69 \mathrm{~m}$ above sea level). The pond was created, possibly as early as the 
late seventeenth century $\mathrm{AD}$, by impoundment of a stream that drains the southern slopes of Hampstead Heath. The small catchment $\left(0.7 \mathrm{~km}^{2}\right)$ consists of open parkland, woodland, and housing (late-nineteenth-century stock) with gardens. The pond is the lowest in a chain of three water bodies, separated by embankments and connected by drains and culverts. In the upper part of the catchment, some sections of streams are open and in semi-natural woodland. The open parkland west of the pond was used historically for seasonal fairs. Public swimming and coarse fishing occur in the two ponds upstream.

\section{Materials and methods}

Sediment analysis and chronological framework

A 6-cm-internal-diameter piston corer was used to collect a 212-cm sediment core (HAMP1) in $2.7 \mathrm{~m}$ water depth in June 2009 (Hall 2013). The core was extruded for multi-proxy analyses at 1-cm intervals. The core was extruded and sliced in the field using a stainless-steel blade and 1-cm-thick ring of core tube that captured mud during vertical extrusion at measured $1-\mathrm{cm}$ intervals. These tools were rinsed with tap water between collection of core slices, which were stored in individual twist-tie PVC bags. The core was measured for ${ }^{210} \mathrm{~Pb},{ }^{226} \mathrm{Ra},{ }^{137} \mathrm{Cs}$ and ${ }^{241} \mathrm{Am}$ activities (Electronic Supplementary Material [ESM] 1) by direct gamma assay, using an ORTEC HPGe GWL series well-type coaxial low-background intrinsic germanium detector (Appleby et al. 1986). ${ }^{210} \mathrm{~Pb}$ activity was determined via its gamma emissions at $46.5 \mathrm{keV}$, and ${ }^{226} \mathrm{Ra}$ by $295 \mathrm{keV}$ and $352 \mathrm{keV}$ gamma emissions from its daughter isotope ${ }^{214} \mathrm{~Pb}$, following 3 weeks in air-tight containers to allow radioactive equilibration. ${ }^{137} \mathrm{Cs}$ and ${ }^{241} \mathrm{Am}$ were determined by their emissions at $662 \mathrm{keV}$ and $59.5 \mathrm{keV}$, respectively. Corrections were made for the effect of selfabsorption of low-energy gamma rays within the sample. The core chronology was calculated using the constant rate of supply (CRS) ${ }^{210} \mathrm{~Pb}$ dating model (Appleby 2001), with reference to the 1963 fallout maximum of ${ }^{137} \mathrm{Cs}$ and ${ }^{241} \mathrm{Am}$ derived from nuclear bomb tests (Appleby et al. 1986). Radionuclide dating of the core was complemented by a spheroidal carbonaceous particle (SCPs) chronology. SCP analysis followed Rose (1994), with identification using criteria described in Rose (2008).

Organic matter content was estimated on contiguous $1-\mathrm{cm}$ samples by weight loss following heating (loss on ignition, LOI) at $550{ }^{\circ} \mathrm{C}$ for $2 \mathrm{~h}$ (Heiri et al. 2001). Downcore wet density measurements at $2-\mathrm{cm}$ intervals were completed by weighing a $2-\mathrm{cm}^{3}$ vial of wet sediment. Sediment samples (contiguous $1-\mathrm{cm}$ samples, 0-20 cm; 2-cm intervals 20-212 cm) were analysed for element abundances using a Spectro XLAB2000 X-ray fluorescence (XRF) spectrometer. $1 \mathrm{~g}$ d.w. (weighed to 4 d.p.) of freeze-dried and milled sediment was placed in nylon cups with a base of prolene foil ( $4 \mu \mathrm{m}$ thickness). Two reference sediment samples, JLK-1 (Imai et al. 1996), of the same mass were measured every 9th sample, to identify instrument drift error and assess measurement accuracy. Recovery rates for elements $\mathrm{Ti}$ (\% d.w.), $\mathrm{Zn}$ and $\mathrm{Pb}$ ( $\mu \mathrm{g} \mathrm{g}^{-1}$ d.w.) in this study, were $112.0 \%, 97.9 \%$ and $113.8 \%$, respectively (Hall 2013).

\section{Microplastic extraction}

Prior experience with extracting low numbers of microplastic particles $(<20$ per $100 \mathrm{~g}$ d.w. $)$ from littoral sediments of an urban UK lake (Vaughan et al. 2017), and small volumes of mud as a consequence of HAMP1 having been used for multiple analyses, required $1-\mathrm{cm}$ core intervals be combined into $5-\mathrm{cm}$ depth intervals (Table 1). Combined sediment samples were mixed before oven drying $\left(48 \mathrm{~h}, 40{ }^{\circ} \mathrm{C}\right)$ for dry mass calculation. Dried sample masses ranged from 20 to $90 \mathrm{~g}$ dry mass. The dried sample was disaggregated with deionised water and washed through $1-\mathrm{mm}$ and $500-\mu \mathrm{m}$ stainless steel sieves, again with deionised water. The $>1-\mathrm{mm}$ and $1-\mathrm{mm}$ to $500-\mu \mathrm{m}$ fractions retained from each sample were collected for analysis. For two samples (ESM 2) the $<500-\mu \mathrm{m}$ fraction was also retained to check microplastic presence in this finer fraction. The focus on the $1-\mathrm{mm}$ to $500-\mu \mathrm{m}$ size range was selected to remove fine silts and clays, while retaining easily visible microplastics for microscopic assessment and Raman spectroscopy (Horton et al. 2017a; Vaughan et al. 2017).

Ten $\mathrm{mL}$ of sodium polytungstate (SPT) solution ( $2.1 \mathrm{~g} \mathrm{~cm}^{-3}$ density) was added to a $50-\mathrm{mL}$ centrifuge tube. This solution was used, as most common polymers remain buoyant at this density 
Table 1 Dated time intervals used for microplastic (MP) assessment

\begin{tabular}{|c|c|c|c|c|c|}
\hline \multicolumn{4}{|c|}{${ }^{210} \mathrm{~Pb}$ dating and sedimentation rate } & \multirow[t]{2}{*}{ MP depths } & \multirow[t]{2}{*}{ MP time periods } \\
\hline Depth $(\mathrm{cm})$ & Year AD & $\mathrm{g} \mathrm{cm}^{-2} \mathrm{yr}^{-1}$ & $\mathrm{~cm} \mathrm{yr}^{-1}$ & & \\
\hline $0-1$ & $2009 \pm 2$ & 0.1827 & 1.261 & $\begin{array}{l}0-5^{\mathrm{a}} \\
5-10^{\mathrm{a}}\end{array}$ & $\begin{array}{l}2009-2005 \\
2005-2000\end{array}$ \\
\hline $10-11$ & $2000 \pm 2$ & 0.167 & 0.951 & $\begin{array}{l}10-15^{\mathrm{a}} \\
15-20^{\mathrm{a}}\end{array}$ & $\begin{array}{l}\text { Mid-late 1990s } \\
\text { Early-Mid 1990s }\end{array}$ \\
\hline $20-21$ & $1989 \pm 3$ & 0.1838 & 0.942 & $\begin{array}{l}20-25^{\mathrm{a}} \\
25-30^{\mathrm{a}}\end{array}$ & $\begin{array}{l}\text { Mid-late 1980s } \\
\text { Mid-early 1980s }\end{array}$ \\
\hline $30-31$ & $1978 \pm 4$ & 0.1554 & 0.761 & $\begin{array}{l}30-35^{\mathrm{a}} \\
35-40^{\mathrm{a}}\end{array}$ & $\begin{array}{l}\text { Late } 1970 \mathrm{~s}-1960 \mathrm{~s} \\
\text { Late } 1960 \mathrm{~s}-\text { early } 1960 \mathrm{~s}\end{array}$ \\
\hline $40-41$ & $1963 \pm 5$ & 0.1466 & 0.627 & $\begin{array}{l}40-45^{\mathrm{a}} \\
45-50^{\mathrm{a}}\end{array}$ & $\begin{array}{l}\text { Early } 1960 \text { s-mid } 1950 \text { s } \\
\text { Mid } 1950 \text { s to } 1940 \text { s }\end{array}$ \\
\hline $50-51$ & $1935 \pm 15$ & 0.0486 & 0.193 & $\begin{array}{l}50-55 \\
55-60\end{array}$ & $\begin{array}{l}1940 s-1930 s \\
1930 s\end{array}$ \\
\hline $70-75$ & & & & $70-75$ & Early twentieth century \\
\hline $80-85$ & & & & $80-85$ & Late nineteenth century \\
\hline $90-95$ & & & & $90-95$ & $\sim$ Nineteenth century \\
\hline
\end{tabular}

(Scientificpolymer.com 2013; Nuelle et al. 2014) except polytetrafluoroethylenes (PTFE) and some composites. Solutions rinsed from the sieves with deionised water were gently poured on top of the SPT solution. The $50-\mathrm{mL}$ tubes were capped and centrifuged at $1500 \mathrm{rpm}$ for $5 \mathrm{~min}$. Each lower-density fraction, containing the microplastics, was pipetted off and vacuum-filtered through a $0.45-\mu \mathrm{m}$ micropore filter paper. Filter papers were covered by a watch glass and oven-dried at $40{ }^{\circ} \mathrm{C}$ before microscopic inspection. Sieves, pipettes and centrifuge tubes (following SPT treatment) were rinsed $(3 \times)$ with deionized water to prevent particles from adhering to surfaces (Hidalgo-Ruz et al. 2012). Between samples, all sieves and vacuum filter equipment were washed and backwashed three times. Blank samples of deionised water were also passed through the sieves and floated on top of SPT before being transferred to vacuum filter papers every 5th sample to check for contamination (ESM 2).

The filter papers were examined at up to $40 \times$ magnification with a stereomicroscope (Leica M60, Germany), with selected particles transferred by stainless steel forceps into covered, white cardboard trays for storage. Microplastics were distinguishable and selected using the following criteria (Hidalgo-Ruz et al. 2012; Nor and Obbard 2014; Horton et al. 2017b): (1) bright/unnatural coloured granules, films and fibres; (2) granules, films and fibres not visibly organic or cellular and (3) microparticles selected by the above criteria that maintain integrity when gently stretched and are elastic when squeezed with forceps. Fibres were inspected for changing thickness along their length and any branching that would suggest organic origin (hairs, root/plant fibres). If branching was present, such fibres were rejected. Particle colour was noted and the longest dimension measured using a 1-mm gridded sheet or microscope graticule. Fibres were stretched by forceps to measure maximum length. Plant root/leaf fibres were distinguishable by their brown/woody colour, branching features and low tensile strength.

The effectiveness of the method was assessed by visual inspection of microplastics present in the $>1$ $\mathrm{mm}$ and $<500-\mu \mathrm{m}$ sieved fractions and also in the remaining, $>2.1 \mathrm{~g} \mathrm{~cm}^{-3}$ solution, following SPT flotation and centrifuging. This was to check for presence of macroplastics in the coarser sediment matrix, $<500-\mu \mathrm{m}$ microplastics, and whether any dense microplastic particles had sunk during density separation. The $>1-\mathrm{mm}$ and $<500-\mu \mathrm{m}$ sieved fractions of each sample were rinsed with deionised water, SPT-treated and vacuum-filtered through $0.45-\mu \mathrm{m}$ filter papers and oven-dried before inspection and particle selection as described above. Denser sediment and SPT solution remaining in the centrifuge tube was 
rinsed with deionised water, vacuum-filtered and dried as above for each sample. The few microplastics in the $>1-\mathrm{mm}$ sieve fraction were added to the sample counts of the 1-mm to $500-\mu \mathrm{m}$ fraction. Microplastic counts in the $<500-\mu \mathrm{m}$ fraction of two samples $(0-5 \mathrm{~cm}$ and $35-40 \mathrm{~cm})$ and in the post-centrifuging SPT solution (ESM 2 and 3) were not included in calculations or Raman composition assessment. Concentrations of particles were calculated as numbers of particles per dry mass of sediment analysed ( $n$ particles $\left.\mathrm{kg}^{-1}\right)$. Microplastic accumulation rates $\left(n \mathrm{~m}^{-2} \mathrm{yr}^{-1}\right)$ were calculated by multiplying concentration by the ${ }^{210} \mathrm{~Pb}$-derived sediment accumulation rate (Table 1).

\section{Contamination control and blank processing}

Incorporation of contaminant microplastics into sediment samples during laboratory processing (Willis et al. 2017) is of particular concern for stratigraphic studies. Potential microplastic contamination can occur during core collection (from clothing, ropes, atmospheric deposition) and laboratory processing. Core HAMP1 was collected using protocols for paleoenvironmental and trace metal work that employ clean materials during core slicing and avoid sediment transported downward during core collection and extrusion. In the laboratory, a white cotton coat was worn to avoid synthetic clothing to sample transfer. Metal sieves were washed and back-washed in deionized water prior to use and kept covered when not in use. The vacuum filter flask (moulded transparent polysulfone, 'Nalgene ${ }^{\circledR}$ ') was similarly washed, before and between samples, with deionized water and covered while in use to avoid airborne dust.

Three blanks of deionized water were run as samples through the whole sieving, density separation and filtration process (ESM 2). The numbers of microplastics in the blanks were low (2 to 3 white, red or blue coloured fibres) and comparable to previous blank numbers run in the same laboratory (Vaughan et al. 2017). These low numbers are significant, however, given the presence of comparable numbers of fibres found in pre-twentieth century and younger HAMP1 sediments. Numbers of fibres in the sediment reported are therefore calculated minus the total number ( +1 for caution) of fibre types found in the blanks (ESM 2). Other particles were not found in the blanks.
Microplastic composition

Only the upper $50 \mathrm{~cm}$ of the core was selected for Raman analysis, as plastic was expected to have only been deposited in significant amounts after the midtwentieth century. Subsamples of particles taken from the $>1-\mathrm{mm}$ and $1-\mathrm{mm}$ to $500-\mu \mathrm{m}$ fractions were analysed by Raman spectroscopy (HR800UV, JobinYvon Horiba, with an integrated Olympus BX21 microscope). Particles were selected to represent the range of shapes and colours found in the sample. A minimum of $20 \%$ of the particles from each sample were analysed. Where highly diverse particle shapes and colours were present, more particles were analysed to give a better representation of particle types, up to a maximum of $66 \%$ particles from one sample (ESM 4).

Spectra were obtained using a near-infrared laser $(785 \mathrm{~nm})$. Acquisition time was $40 \mathrm{~s}$ and accumulation was set at $2 \times$, with the range set to acquire between 200 and $3200 \mathrm{~cm}^{-1}$ to account for the entire polymer spectrum. Depending on particle colour, laser intensity was adjusted accordingly, to prevent particle damage by the laser. The spectra were analysed using the BioRad KnowItAll ${ }^{\circledR}$ Informatics System-Raman ID Expert (2015) software. This allowed automatic and manual matching of unknown spectra to known compounds within the Biorad KnowItAll ${ }^{\circledR}$ Raman database (containing $>24,000$ known compounds). The most suitable match was identified based on corresponding peak positions. For a more detailed description of identification methods see Horton et al. (2017a).

\section{Results}

\section{Core chronology}

Unsupported ${ }^{210} \mathrm{~Pb}$ and ${ }^{137} \mathrm{Cs}$ activities provide a reliable sediment chronology post $1935 \pm 15(50 \mathrm{~cm}$ depth). Between $1935 \pm 15(50 \mathrm{~cm})$ and $1963 \pm 5$ $(40 \mathrm{~cm})$, sediment accumulation was low $\left(0.0486 \mathrm{~g} \mathrm{~cm}^{-2} \mathrm{yr}^{-1} ; 0.193 \mathrm{~cm} \mathrm{yr}^{-1}\right)$. Sediment accumulation since $1963 \pm 5$ has been relatively uniform, with a mean rate of $0.167 \mathrm{~g} \mathrm{~cm}^{-2} \mathrm{yr}^{-1}$ (Table 1). Below $40 \mathrm{~cm}$, particularly between 40 and $110 \mathrm{~cm}$, there is little net decline in unsupported ${ }^{210} \mathrm{~Pb}$, 
which may indicate some sediment mixing (ESM 1). Profiles of both LOI 550 and $\mathrm{Ti}$ concentrations (Fig. 1), however, show that if a hiatus or mixing occurred, the sediment sources and the depositional environment remained similar.

Assigned dates below $50 \mathrm{~cm}$ are derived from $1935 \pm 15$ sedimentation rates and historical records of SCP and trace metal concentrations in other ${ }^{210} \mathrm{~Pb}$ dated core sequences from London (Hall 2013). Very low concentrations of SCPs are found in HAMP1 below $100 \mathrm{~cm}$ depth, indicating a mid-late nineteenthcentury age, but they increase above $90 \mathrm{~cm}$, most likely signifying the late nineteenth- to twentiethcentury expansion of small-scale power generation plants in London at that time (Rose and Appleby 2005). The concomitant increase in $\mathrm{Zn}$ and $\mathrm{Pb}$ in the core (Fig. 1) from the late-nineteenth century and their tracking of the increase in SCPs to their peak in the mid-1970s also supports evidence of historical lakesediment trace-metal accumulation from fossil-fuel combustion in London (Hall 2013).
Microplastic abundance

The assemblage of microplastics recovered from HAMP1 core samples is dominated by fibres (40-100\% of particles, variable by slice) (Table 2). Microplastic fragments were identified only in sediments younger than the late $1950 \mathrm{~s}(45-40 \mathrm{~cm})$. Fibres occur in samples down to $95 \mathrm{~cm}$ that match microplastic features identified in younger sediments by Raman spectroscopy. Fibres were found both entwined with particles of mud/organic matter and on their own. Many fibres were visibly twisted, knotted and showed signs of abrasion/tearing (Fig. 2). The smallest fibres observed were $\sim 100 \mu \mathrm{m}$. Calculation of the abundance of fibres in relation to numbers found in the associated blanks, show red, blue and white fibres (ESM 2) in sediments below $45 \mathrm{~cm}$ occur at near or non-detectable/below blank level (Fig. 1).

Microplastic concentration calculated for each depth/age interval assumes that microplastics are uniformly distributed through the whole core slice. Total microplastic maximum concentrations, equating

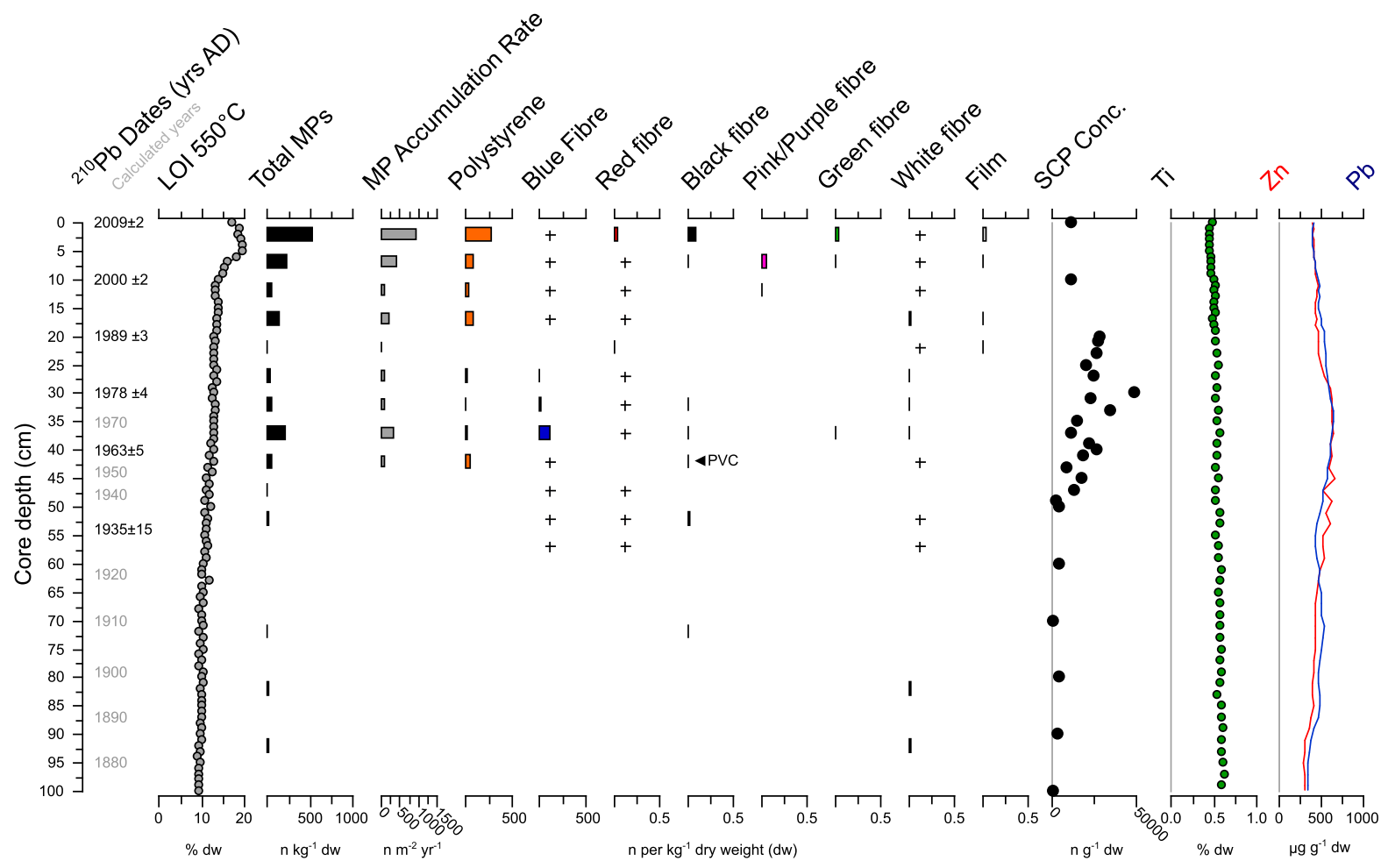

Fig. 1 Stratigraphic plot of ${ }^{210} \mathrm{~Pb}$-dated sediment variables and occurrence of microplastic (MP) types in core HAMP1. Crosses indicate below-blank occurrence. LOI $550{ }^{\circ} \mathrm{C}$ (dry mass loss on ignition); SCP Conc (spheroidal carbonaceous particle concentration); $\mathrm{Ti}, \mathrm{Zn}$ and $\mathrm{Pb}$ element abundance in sediment samples measured by XRF (see text) 
Table 2 Colour and size classification summary of materials found in (a) 500- $\mu \mathrm{m}$ to $1-\mathrm{mm}$ and (b) $>1-\mathrm{mm}$ sieved fractions following SPT flotation. Fibres, measured length; Fragments*, longest axis. Total Microplastic (TMP) concentration includes all particles and synthetic fibres. TMP-blank concentrations (italics) calculated by subtracting fibre numbers found in blanks (ESM 2)

\begin{tabular}{|c|c|c|c|c|c|c|c|c|c|c|c|c|c|c|}
\hline \multirow{3}{*}{$\begin{array}{l}\text { Time periods } \\
\text { Depth }\end{array}$} & \multicolumn{2}{|c|}{ 2009-2005 } & \multicolumn{2}{|c|}{$2005-2000$} & \multicolumn{2}{|c|}{$\begin{array}{l}\text { Mid-late } \\
\text { 1990s }\end{array}$} & \multicolumn{2}{|c|}{$\begin{array}{l}\text { Early-mid } \\
1990 \mathrm{~s}\end{array}$} & \multicolumn{2}{|c|}{$\begin{array}{l}\text { Mid-late } \\
1980 \text { s }\end{array}$} & \multicolumn{2}{|c|}{$\begin{array}{l}\text { Mid-early } \\
\text { 1980s }\end{array}$} & \multicolumn{2}{|c|}{$\begin{array}{l}\text { Late 1970s- } \\
1960 \mathrm{~s}\end{array}$} \\
\hline & \multicolumn{2}{|c|}{$0-5$} & \multicolumn{2}{|c|}{$5-10$} & \multicolumn{2}{|c|}{$10-15$} & \multicolumn{2}{|c|}{$15-20$} & \multicolumn{2}{|c|}{$20-25$} & \multicolumn{2}{|c|}{$25-30$} & \multicolumn{2}{|c|}{$30-35$} \\
\hline & (a) & (b) & (a) & (b) & (a) & (b) & (a) & (b) & (a) & (b) & (a) & (b) & (a) & (b) \\
\hline \multicolumn{15}{|l|}{ Fibres (n) } \\
\hline Blue & & 3 & 1 & 1 & & 1 & & 1 & & & 2 & 2 & 5 & 1 \\
\hline Red & 3 & 1 & 1 & 1 & 1 & & 1 & 2 & 3 & 1 & & 1 & 2 & \\
\hline White & & 1 & & 2 & & 1 & & 4 & 1 & & & 3 & & 3 \\
\hline Black & & 2 & & 1 & & & & & & & & & & 1 \\
\hline Green & & 1 & 1 & & & & & & & & & & & \\
\hline Pink/purple & & & 1 & 2 & 1 & & & & & & & & & \\
\hline
\end{tabular}

\section{Fragments (n)}

Orange foam* $5 \quad 1$

Film*

Dry mass $(\mathrm{g}) \quad 20.4$

TMP (n) $\quad 18$

TMP minus blank 11

$8 \quad 16$

TMP $\left(\mathrm{n} \mathrm{kg}^{-1}\right) \quad 882.4$

$10 \quad 3$

TMP minus blank 539.2

$388.3 \quad 128.3$

25

242.7

\begin{tabular}{ll}
\hline Time periods & Late \\
& $\begin{array}{l}1960 \mathrm{~s}- \\
\text { early } 1960 \mathrm{~s}\end{array}$ \\
& \\
Depth & $35-40$
\end{tabular}

(a) (b)

46.7

$1950 \mathrm{~s}-1940 \mathrm{~s}$

40-45

$1940 \mathrm{~s}$

(a) (b)

(a) (b)

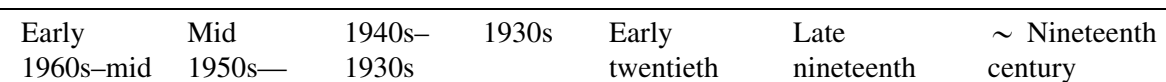

1

2

1

50-55

$\overline{55-60} \frac{\text { century }}{70-75}$ century

(a) (b)

(a) (b)

(a)

(b)

80-85

67.8

76.7

$14 \quad 6$

10

13

46

\section{Fibres (n)}

Blue

Red

$$
12
$$

2

White

1

Black

Green

Pink/purple

\section{Fragments (n)}

Orange foam* 3

34

Film*

Dry mass $(\mathrm{g}) \quad 83.9 \quad 70$

TMP (n) $\quad 25$

TMP minus blank 19

TMP $\left(\mathrm{n} \mathrm{kg}^{-1}\right) \quad 297.8$

7

TMP minus blank 226.4

$5 \quad 1$

$99.4 \quad 38.6$

77.7
3
1
38.6
12.9

$\begin{array}{lll}56.5 & 60.3 & 71.1 \\ 5 & 2 & 4 \\ 2 & 0 & 1 \\ 88.5 & 33.2 & 56.2 \\ 35.4 & 0 & 14.1\end{array}$

72.3

89.9

71

12.9

(a) (b)

b) (a)

(a)

(b)

(a) (b)


Fig. 2 Selected microplastic particles and fibres found in HAMP1 core

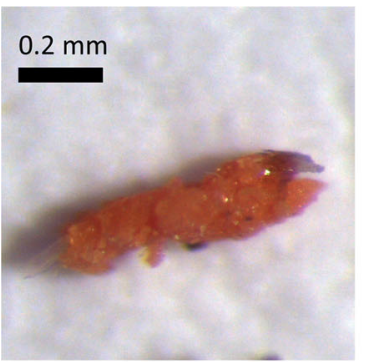

(a) $0-5 \mathrm{~cm}$ (2009-2005) Polystyrene

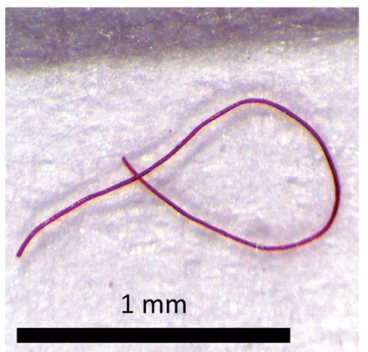

(d) $15-20 \mathrm{~cm}$ (mid-late 1990s) Red fibre

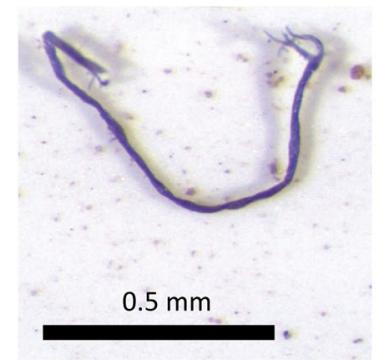

(g) $50-55 \mathrm{~cm}$ (1930s-1940s) Indigo polymer

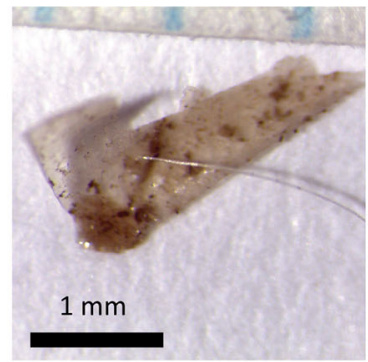

(b) $0-5 \mathrm{~cm}$ (2009-2005) Starch polymer

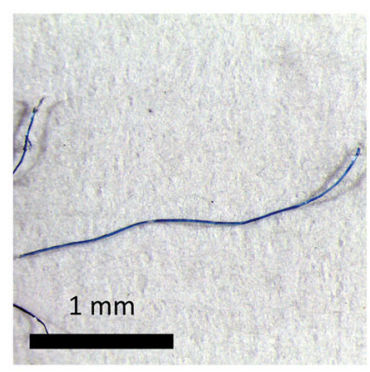

(e) $25-30 \mathrm{~cm}$ (Mid-Early 1980s) Indigo pigment polymer

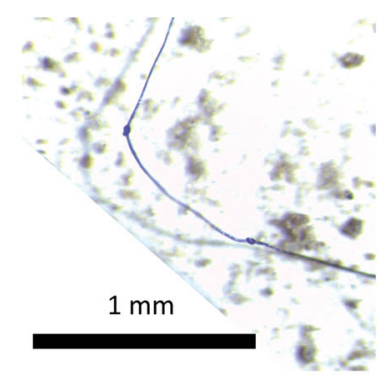

(h) $70-75 \mathrm{~cm}$ (Early 20th C.) Knotted polymer

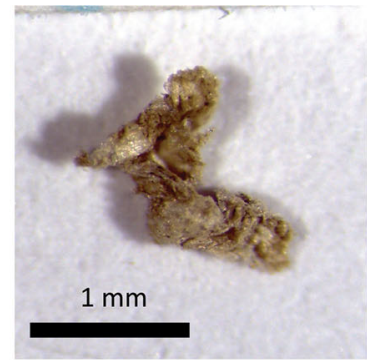

(c) $5-10 \mathrm{~cm}(2005-2000)$ Polystyrene

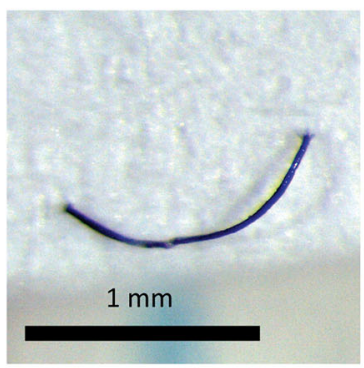

(f) $35-40 \mathrm{~cm}$ (Late-Early 1960s) Indigo (twisted polymer)

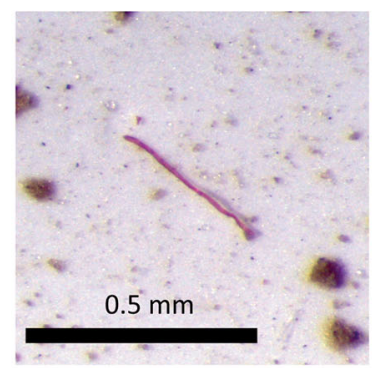

(i) $90-95 \mathrm{~cm}$ ( 19th C) Red fibre to 539 particles per $\mathrm{kg}^{-1}$ dry weight, occurred in sediment deposited between 2005 and 2009. Total microplastic concentration decreased below the surface (242 particles $\mathrm{kg}^{-1}, 2000-2005$ ) and further declined to 16 particles $\mathrm{kg}^{-1}$ in the late-to-mid-1980s, before increasing (226 particles $\mathrm{kg}^{-1}$ ) in the late-mid 1960s. This latter sample had the greatest number of fibres in any of the depth intervals (Table 2). Total microplastic concentrations were low $(<70$ particles $\mathrm{kg}^{-1}$ ) in sediments dated between the nineteenth century and mid-1960s. Accumulation rates of total microplastics were low in the mid-1950s to 1960s (104 particles $\mathrm{m}^{-2} \mathrm{yr}^{-1}$ ) with a mid-late-1960s plastic accumulation peak (Fig. 2) equating to 350 particles $\mathrm{m}^{-2} \mathrm{yr}^{-1}$. Accumulation rates in the surface $5 \mathrm{~cm}$ (2005 to 2009) are three times higher than those in the mid-late 1960s (984 particles $\mathrm{m}^{-2} \mathrm{yr}^{-1}$ ). Microplastics observed in the $>1$-mm sieved fraction, except for one orange fragment in the surface sample, were fibres. Three and one red fibres were found in the 0-5 cm and 35-40 cm sample depths, respectively, in the $<500-\mu \mathrm{m}$ fractions (ESM 2). Extrapolating the number of microplastic particles in HAMP1 core samples to the whole lake points to a conservative estimate of hundreds of millions of microplastic 
particles incorporated into the benthic sediment of Hampstead Pond No. 1.

Microplastic fibre colour and composition

The majority of microplastics retained by the $1-\mathrm{mm}$ and 500- $\mu \mathrm{m}$ sieves were different-coloured fibres, $<$ $5 \mathrm{~mm}$ in length. Blue fibres were, overall, the most abundant in the sediments (25\% particles), followed by white $(22 \%)$, red $(17 \%)$, black $(8 \%)$, pink/purple $(3 \%)$ and green/turquoise (2\%). Blue, red and white fibres were, however, the only coloured fibres found in the blanks, which indicate their likely prevalence as contaminants in the sediment samples. White fibres are especially problematic as they occurred above blank levels in older nineteenth-century sediments, suggesting either systematic contamination or error in their characterization as synthetic fibres.

A few blue fibres generated spectra characteristic of artificial dyes; indigo and Deorlin blue-but the majority of blue fibres remained unidentified (Table 3). Synthetic dye compounds (Indigo, Evans blue), rather than polymer composition, were similarly identified for black fibres, although one black fibre was identified as PVC in sediment from the mid 1950searly 1960s (Table 3, highlighted on Fig. 1). Spectra for red fibres analysed were matched to a nitrocellulose composite with red pigment and polysulphide rubber (although this match was not conclusive). Measured white/clear and pink-coloured fibres comprised polyacrylonitrile composites (Table 3). Natural polymers identified were polymerisable starch and mucopolysaccharides (Fig. 2b) in the top $10 \mathrm{~cm}$. Synthetic polymers or substances dominated the identifiable composition of the fibres examined by Raman spectroscopy (90\%).

Non-fibre microplastics

Compared to the relative abundance of fibres in the sediments, the only fragments found were distinct orange $(0.2-2 \mathrm{~mm})$, foam-like particles and a crumpled film particle (Fig. 2a, c). Orange particles were found only in sediments younger than the early 1950s1960s (57 particles $\mathrm{kg}^{-1}$ ), with a maximum in the surface $5 \mathrm{~cm}$ (294 particles $\mathrm{kg}^{-1}$ ). The orange particles have a vesicular/crumb-like texture and deform when squeezed. Representative samples of these orange foamlike particles and the crumpled film were found to be polystyrene, with various copolymers (Table 3). The accumulation rate of microplastic polystyrene indicates a decline from its appearance in the early 1960s $\left(80 \mathrm{~m}^{-2} \mathrm{yr}^{-1}\right)$ to the middle $1980 \mathrm{~s}$ (not found), before increasing to the surface $\left(540 \mathrm{~m}^{-2}\right.$ $\left.\mathrm{yr}^{-1}\right)$.

\section{Discussion}

Temporal patterns in microplastic abundance

Low numbers (above blank) of largely unconfirmedcomposition synthetic fibres, particles of polystyrene and other polymers comprise the sedimentary sequence of microplastics in HAMP1. Excluding unconfirmed synthetic fibre types as microplastics has a significant effect on microplastic concentration; between 20 and $100 \%$ reduction in this study. Synthetic fibres are prevalent in microplastic studies of lacustrine and other freshwater surface sediments (Free et al. 2014; Baldwin et al. 2016; Ballent et al. 2016; Fischer et al. 2016; Su et al. 2016; Vaughan et al. 2017). Derived from the breakdown of synthetic textiles, they are released directly into freshwaters with industrial and domestic wastewater (Napper and Thompson 2016; Miller et al. 2017) and via treated wastewater and reworked sewage sludge spread on agricultural land (Zubris and Richards 2005). Wastewater and sewage inputs of microplastic and synthetic fibres into Hampstead Pond No. 1 are likely to have been low because of the pond's small, parkland catchment. Other sources of fibres could be those shed from clothing and textiles, synthetic swimwear and fishing line used in upstream ponds. Prevalence of fibres in Hampstead Pond No. 1 may also be from breakdown products of woven synthetic fabrics, released by degradation processes occurring in the lake and along the shoreline of the two upstream ponds.

Benthic sediment microplastic concentrations (maximum 539 particles $\mathrm{kg}^{-1}$ ) in HAMP1 are generally comparable to the number of particles reported in surface sediments of Lake Ontario, Canada (87-616 particles $\mathrm{kg}^{-1}$ ) (Corcoran et al. 2015), Tai Hu, China $\left(11-234.6 \mathrm{~kg}^{-1}\right)$ (Su et al. 2016) and lakes in central Italy (109-266 particles $\mathrm{kg}^{-1}$ ) (Fischer et al. 2016), but an order of magnitude lower than the number of plastic particles found in lake sediments of the 
Table 3 Raman compositional analysis results; identified, $(\bigcirc)$ identified but not $100 \%$ conclusive, $(\square)$ Peaks visible, but not able to interpret, $(\square)$ no visible peaks therefore unidentifiable

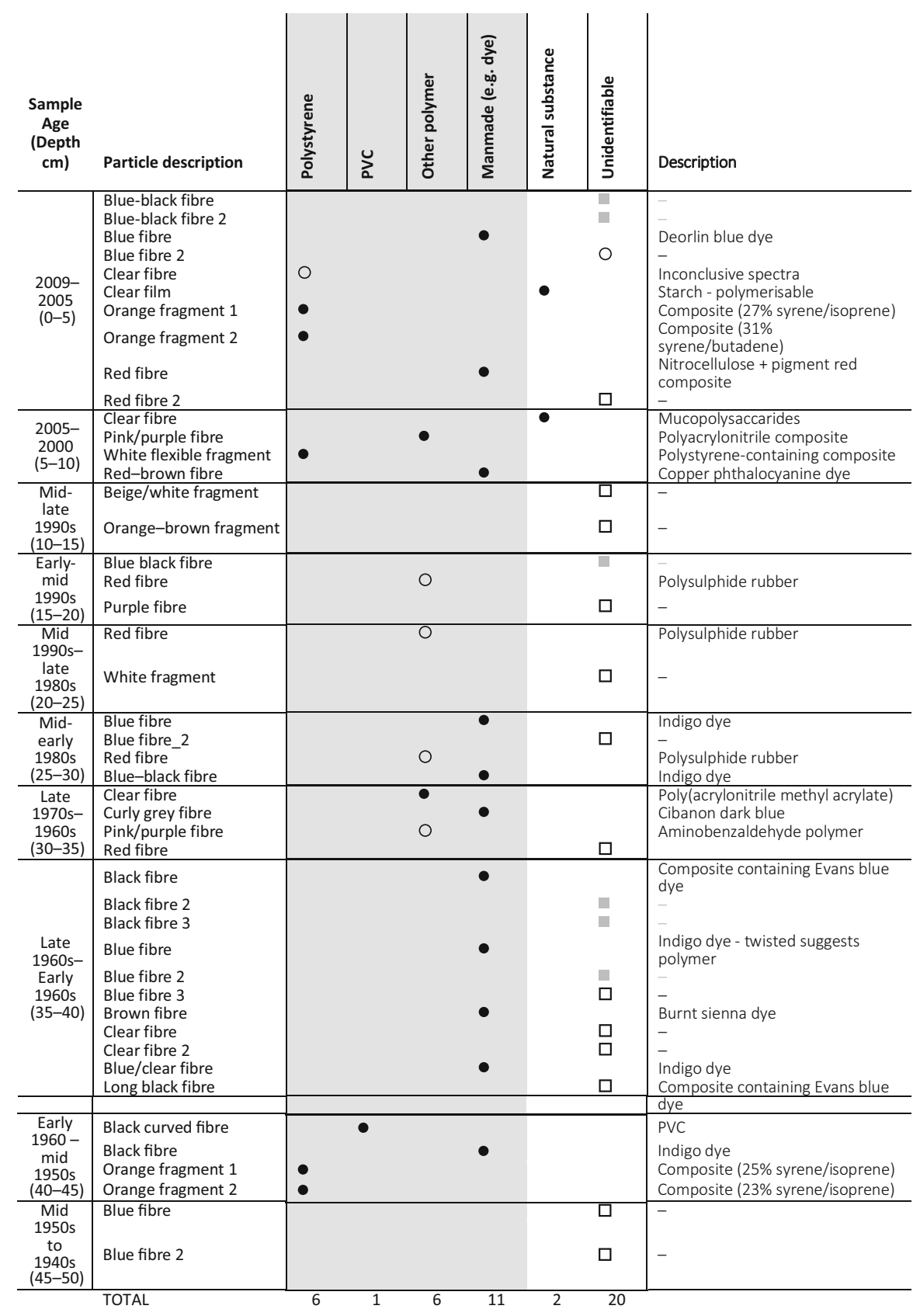

Sakurada-bori moat in Tokyo (1845-5385 particles $\mathrm{kg}^{-1}$ ) that receives street runoff and combined sewer overflow (Matsuguma et al. 2017). Although the increased particle and fibre concentration in the upper $10 \mathrm{~cm}$ may be concomitant with the slightly more organic (15-20\% LOI) sediment in the top of the core (Fig. 1), this effect is not observed in the increased fibre concentration of the 1950s-1960s (35-45 cm). This earlier increase in fibre concentration coincides with the first occurrence of orange polystyrene 
particles and significant above-blank abundance of blue and black fibres (dyes/polymers). This coincidence of particle composition and significant concentration increase corresponds with the start of global mass production, use and waste-generation of plastic (Barnes et al. 2009; Zalasiewicz et al. 2016; Geyer et al. 2017).

It is apparent that the record of accumulation in HAMP1 does not follow the exponential historical increase in global plastic production (Thompson et al. 2004; Zalasiewicz et al. 2016). Unlike large-catchment, continental lakes (e.g. Lake Ontario, USCanada) and marine basins that receive expansive atmospheric and wastewater sources, where the proportion of different microplastics is more commensurate with national production patterns (Corcoran et al. 2015), microplastic abundance and types in small catchments of lakes with limited wastewater inputs such as Hampstead No. 1 Pond are influenced far more by local sources and atmospheric deposition (Dris et al. 2016). These differences among types, sources and transport modes must be considered if a 'plastic horizon' (Corcoran et al. 2014, 2015) is to be used to define or signpost the Anthropocene (Zalasiewicz et al. 2016).

The colour range of fibres found at depth in the Hampstead No.1 Pond core is like that found in previous microplastic surveys, i.e. black, red, white and blue. Colour alone provides ambiguous information regarding the origin of the fibres, as the range of synthetic fabrics (clothes, carpets, ropes) that shed fibres is vast (Browne et al. 2011; Boucher et al. 2017), but placed in a stratigraphic sequence may provide insights into historical changes in microplastic sources to benthic lake sediments (ESM 5).

Discounting the low number found in pre-twentieth-century mud and likely occurrence from modern contamination (Woodall et al. 2015; Wesch et al. 2017; Willis et al. 2017), it may be significant that the few coloured fibres found were red. Fibres of the same colour and form were identified in the upper $50 \mathrm{~cm}$ of the core as possibly being made of polysulphide rubber (Table 2). This is an early family of plastics used in hoses and linings of gas/water-tight fabrics. The move towards blue fibres, peaking in the 1960s, followed by a post-1970s decline in concentration of fibres containing synthetic dyes, might reflect trends in fashion and fabric use (Schneider 1994). We observed the presence of indigo, a common synthetic dye used for polyester and cotton. Twisted forms (McIntyre 2004) (Fig. 2e-h) and high tensile strength noted during microscope selection, however, suggest these blue fibres are synthetic polymers (Burkinshaw 1995; Kunttou et al. 2005; Nor and Obbard 2014). Separating synthetically dyed organic fibres from synthetic fibres can be achieved using chemical digestion (e.g. peroxide or nitric acid) techniques (Nuelle et al. 2014), but was not done in this study because of potential discoloration (bleaching) effects, and the fact that multiple treatments are often required to remove all organic matter from benthic lake sediments. Polyacrylonitrile polymer fibres found in both 1960s1970s $(30-35 \mathrm{~cm})$ and $2000-2005(5-10 \mathrm{~cm})$ sediments indicate a half century of acrylic-fibre transport to the lake. Concentrations of identifiable polystyrene (PS) particles found in the core range from 60 particles $\mathrm{kg}^{-1}$ (1950s-1960s) to 300 particles kg ${ }^{-1}$ of sediment in the upper $5 \mathrm{~cm}$. They occur only post-1950, corresponding with their production and usage, up to the present. Orange foam particles were not present in any of the blanks. The concentration of PS particles of homogenous orange and foam-like structure are similar through the core, suggesting a continuous common source of coloured material for the last ca. 50 years. The absence (Table 2) of larger plastic particles in the sediment record reflects the particle sorting that occurs in benthic environments, determined by depth and local wind/current activity (Vaughan et al. 2017), as well as the lake's position at the bottom of a chain of lakes. Only one larger particle $(\sim 2 \mathrm{~mm})$ of orange foam was encountered in the $>1-\mathrm{mm}$ sieved fraction (Table 2).

\section{Methodological limitations}

Only a representative selection of microplastic particles from each sediment depth was analysed by Raman spectroscopy and we recognize that this limits the stratigraphic compositional interpretation. Of the particles selected for Raman analysis, $24 \%$ contained synthetic material (e.g. dyes), $28 \%$ were identified as plastic polymers (ESM 6) and around half (48\%) of the particles were unidentifiable or were natural substances. This proportion of identified versus unidentified particles is common in aquatic microplastic studies using Raman spectroscopy (identified 41-67\%) (Ballent et al. 2016; Clunies-Ross et al. 2016; Frère et al. 2017). Because of the low number 
and size of microplastics found, and the ubiquity of microfibres found in urban atmospheres, contamination during coring and processing (Woodall et al. 2015; Wesch et al. 2017) must be acknowledged as a possible source of error. The number of fibres in the blanks examined during processing, and their potential influence on the interpretation of early plastic occurrence, is recognized.

\section{Conclusions}

This ${ }^{210} \mathrm{~Pb}$-dated sediment-core assessment of microplastic concentrations, colour abundance and measured composition, yielded a realistic stratigraphy of historical microplastic deposition in Hampstead Pond No. 1. Dominance of fibres in the sediment and the lake's geographic position and relative isolation from wastewater inputs suggest that atmospheric fallout was an important source of microplastics.

This study indicated that downcore changes in microplastic abundance, type and colour in a sediment sequence may reflect changes in microplastic production and usage over time. It also showed that routine extraction of microplastics from radionuclide-dated lake sediment cores is feasible and best measured alongside other contaminant and environmental proxies. Possible input of contaminant microplastics to sediments during sampling and processing is recognized as a potential problem, and future stratigraphic work must aim to further improve contaminant reduction and blank-control sample methods. With improved contaminant detection and a greater proportion of microplastic polymers identified, future paleolimnological work will undoubtedly assist in quantifying the historical flux of microplastic waste, from terrestrial, through freshwater, to marine environments.

Acknowledgements The Ph.D. research by Charlotte Hall on HAMP1 was funded by the Open Air Laboratory (OPAL) project through the UK National Lottery and the Big Lottery Fund. Handong Yang in the UCL Environmental Radiometric Facility at University College London is thanked for dating the core and discussion of results. Elma Lahive, CEH Wallingford, is thanked for her contributions to the discussion of results in this paper.

Open Access This article is distributed under the terms of the Creative Commons Attribution 4.0 International License (http:// creativecommons.org/licenses/by/4.0/), which permits unrestricted use, distribution, and reproduction in any medium, provided you give appropriate credit to the original author(s) and the source, provide a link to the Creative Commons license, and indicate if changes were made.

\section{References}

Andrady AL (2003) Plastics and the environment. Wiley, Hoboken

Appleby P (2001) Chronostratigraphic techniques in recent sediments. In: Last WM, Smol JP (eds) Tracking environmental change using lake sediments, Volume 1: basin analysis, coring, and chronological techniques. Kluwer Academic Publishers, Dordrecht, pp 171-203

Appleby P, Nolan P, Gifford D, Godfrey M, Oldfield F, Anderson N, Battarbee RW (1986) ${ }^{210} \mathrm{~Pb}$ dating by low background gamma counting. Hydrobiologia 143:21-27

Baldwin AK, Corsi SR, Mason SA (2016) Plastic debris in 29 great lakes tributaries: relations to watershed attributes and hydrology. Environ Sci Technol 50:10377-10385

Ballent A, Corcoran PL, Madden O, Helm PA, Longstaffe FJ (2016) Sources and sinks of microplastics in Canadian Lake Ontario nearshore, tributary and beach sediments. Mar Pollut Bull 110:383-395

Barnes DKA, Galgani F, Thompson RC, Barlaz M (2009) Accumulation and fragmentation of plastic debris in global environments. Philos Trans R Soc Lond B Biol Sci 364:1985-1998

Blettler MCM, Ulla MA, Rabuffetti AP, Garello N (2017) Plastic pollution in freshwater ecosystems: macro-, meso-, and microplastic debris in a floodplain lake. Environ Monit Assess 189:581

Boucher J, Friot D, Boucher J (2017) Primary microplastics in the oceans: a global evaluation of sources. IUCN, Gland

Boyle JF (2001) Inorganic geochemical methods in paleolimnology. In: Last W, Smol JP (eds) Tracking environmental change using lake sediments, physical and geochemical methods. Kluwer, Dordrecht, pp 83-142

Browne MA, Crump P, Niven SJ, Teuten E, Tonkin A, Galloway T, Thompson R (2011) Accumulation of microplastic on shorelines woldwide: sources and sinks. Environ Sci Technol 45:9175-9179

Burkinshaw SM (1995) Polyester. Chemical principles of synthetic fibre dyeing. Springer, Dordrecht, pp 1-76

Castañeda RA, Avlijas S, Simard MA, Ricciardi A (2014) Microplastic pollution in St. Lawrence river sediments. Can J Fish Aquat Sci 71:1767-1771

Clunies-Ross P, Smith G, Gordon K, Gaw S (2016) Synthetic shorelines in New Zealand? Quantification and characterisation of microplastic pollution on Canterbury's coastlines. N Z J Mar Freshw Res 50:317-325

Corcoran PL, Moore CJ, Jazvac K (2014) An anthropogenic marker horizon in the future rock record. GSA Today 24:4-8

Corcoran PL, Norris T, Ceccanese T, Walzak MJ, Helm PA, Marvin CH (2015) Hidden plastics of Lake Ontario, Canada and their potential preservation in the sediment record. Environ Pollut 204:17-25 
Cundy AB, Collins PE, Turner SD, Croudace IW, Horne D (1998) 100 years of environmental change in a coastal wetland, Augusta Bay, southeast Sicily: evidence from geochemical and palaeoecological studies. Spec Publ Geol Soc Lond 139:243-254

Driedger AG, Dürr HH, Mitchell K, Van Cappellen P (2015) Plastic debris in the Laurentian Great Lakes: a review. J Great Lakes Res 41:9-19

Dris R, Gasperi J, Saad M, Mirande C, Tassin B (2016) Synthetic fibers in atmospheric fallout: a source of microplastics in the environment? Mar Pollut Bull 104:290-293

Eerkes-Medrano D, Thompson RC, Aldridge DC (2015) Microplastics in freshwater systems: a review of the emerging threats, identification of knowledge gaps and prioritisation of research needs. Water Res 75:63-82

Engstrom DR, Rose NL (2013) A whole-basin, mass-balance approach to paleolimnology. J Paleolimnol 49:333-347

Faure F, Demars C, Wieser O, Kunz M, De Alencastro LF (2015) Plastic pollution in Swiss surface waters: nature and concentrations, interaction with pollutants. Environ Chem 12:582-591

Fischer EK, Paglialonga L, Czech E, Tamminga M (2016) Microplastic pollution in lakes and lake shoreline sediments-a case study on Lake Bolsena and Lake Chiusi (central Italy). Environ Pollut 213:648-657

Free CM, Jensen OP, Mason SA, Eriksen M, Williamson NJ, Boldgiv B (2014) High-levels of microplastic pollution in a large, remote, mountain lake. Mar Pollut Bull 85:156-163

Frère L, Paul-Pont I, Rinnert E, Petton S, Jaffré J, Bihannic I, Soudant P, Lambert C, Huvet A (2017) Influence of environmental and anthropogenic factors on the composition, concentration and spatial distribution of microplastics: a case study of the Bay of Brest (Brittany, France). Environ Pollut 225:211-222

Geyer R, Jambeck JR, Law KL (2017) Production, use, and fate of all plastics ever made. Sci Adv 3:e1700782

Hall CJ (2013) Trace metal contamination of lakes and ponds in London. PhD Thesis. University College London

Hardesty BD, Harari J, Isobe A, Lebreton L, Maximenko N, Potemra JT, Vethaak D, Wilcox C (2017) Using numerical model simulations to improve the understanding of microplastic distribution and pathways in the marine environment. Front Mar Sci 4:30

Heiri O, Lotter AF, Lemcke G (2001) Loss on ignition as a method for estimating organic and carbonate content in sediments: reproducibility and comparability of results. J Paleolimnol 25:101-110

Hidalgo-Ruz V, Gutow L, Thompson RC, Thiel M (2012) Microplastics in the marine environment: a review of the methods used for identification and quantification. Environ Sci Technol 46:3060-3075

Horton AA, Dixon SJ (2018) Microplastics: an introduction to environmental transport processes. WIREs Water 5:e1268

Horton AA, Svendsen C, Williams RJ, Spurgeon DJ, Lahive E (2017a) Large microplastic particles in sediments of tributaries of the River Thames, UK-abundance, sources and methods for effective quantification. Mar Pollut Bull 114:218-226

Horton AA, Walton A, Spurgeon DJ, Lahive E, Svendsen C (2017b) Microplastics in freshwater and terrestrial environments: evaluating the current understanding to identify the knowledge gaps and future research priorities. Sci Total Environ 586:127-141

Imai N, Sakuramachi H, Terashima S, Itoh S, Ando A (1996) Database on internet for geological survey of Japan geochemical reference samples. Geostand Geoanal Res 20:161-164

Imhof HK, Wiesheu AC, Anger PM, Niessner R, Ivleva NP, Laforsch C (2018) Variation in plastic abundance at different lake beach zones-a case study. Sci Total Environ 613:530-537

Kunttou K, Hongyo S, Maeda S, Mishima K (2005) Dyeing polyester fabrics with indigo. Text Res J 75:149-153

Lechner A, Keckeis H, Lumesberger-Loisl F, Zens B, Krusch R, Tritthart M, Glas M, Schludermann E (2014) The Danube so colourful: a potpourri of plastic litter outnumbers fish larvae in Europe's second largest river. Environ Pollut 188:177-181

Lobelle D, Cunliffe M (2011) Early microbial biofilm formation on marine plastic debris. Mar Pollut Bull 62:197-200

Martin J, Lusher A, Thompson RC, Morley A (2017) The deposition and accumulation of microplastics in marine sediments and bottom water from the Irish continental shelf. Sci Rep 7:10772

Matsuguma Y, Takada H, Kumata H, Kanke H, Sakurai S, Suzuki T, Itoh M, Okazaki Y, Boonyatumanond R, Zakaria MP (2017) Microplastics in sediment cores from Asia and Africa as indicators of temporal trends in plastic pollution. Arch Environ Contam Toxicol 73:230-239

McIntyre JE (2004) Synthetic fibres: nylon, polyester, acrylic, polyolefin. Elsevier, Amsterdam

Miller RZ, Watts AJ, Winslow BO, Galloway TS, Barrows AP (2017) Mountains to the sea: river study of plastic and nonplastic microfiber pollution in the northeast USA. Mar Pollut Bull 124:245-251

Moore C, Lattin G, Zellers A (2011) Quantity and type of plastic debris flowing from two urban rivers to coastal waters and beaches of Southern California. J Integr Coast Zone Manag 11:65-73

Näkki P, Setälä O, Lehtiniemi M (2017) Bioturbation transports secondary microplastics to deeper layers in soft marine sediments of the northern Baltic Sea. Mar Pollut Bull 119:255-261

Napper IE, Thompson RC (2016) Release of synthetic microplastic plastic fibres from domestic washing machines: effects of fabric type and washing conditions. Mar Pollut Bull 112:39-45

Nor NHM, Obbard JP (2014) Microplastics in Singapore's coastal mangrove ecosystems. Mar Pollut Bull 79:278-283

Nuelle M-T, Dekiff JH, Remy D, Fries E (2014) A new analytical approach for monitoring microplastics in marine sediments. Environ Pollut 184:161-169

Rochman CM, Hoh E, Hentschel BT, Kaye S (2013) Long-term field measurement of sorption of organic contaminants to five types of plastic pellets: implications for plastic marine debris. Environ Sci Technol 47:1646-1654

Rose NL (1994) A note on further refinements to a procedure for the extraction of carbonaceous fly-ash particles from sediments. J Paleolimnol 11:201-204 
Rose NL (2008) Quality control in the analysis of lake sediments for spheroidal carbonaceous particles. Limnol Oceanogr Methods 6:172-179

Rose NL, Appleby P (2005) Regional applications of lake sediment dating by spheroidal carbonaceous particle analysis I: United Kingdom. J Paleolimnol 34:349-361

Sanchez W, Bender C, Porcher J-M (2014) Wild gudgeons (Gobio gobio) from French rivers are contaminated by microplastics: preliminary study and first evidence. Environ Res 128:98-100

Schmidt C, Krauth T, Wagner S (2017) Export of plastic debris by rivers into the sea. Environ Sci Technol 51:12246-12253

Schneider J (1994) In and out of polyester: desire, disdain and global fibre competitions. Anthropol Today 10:2-10

Scientificpolymer.com (2013) Density of polymers (by density). http://scientificpolymer.com/density-of-polymers-bydensity/. Accessed 28 June 2017

Sruthy S, Ramasamy EV (2017) Microplastic pollution in Vembanad Lake, Kerala, India: the first report of microplastics in lake and estuarine sediments in India. Environ Pollut 222:315-322

Su L, Xue Y, Li L, Yang D, Kolandhasamy P, Li D, Shi H (2016) Microplastics in Taihu Lake, China. Environ Pollut 216:711-719

Thompson RC, Olsen Y, Mitchell RP, Davis A, Rowland SJ, John AWG, McGonigle D, Russell AE (2004) Lost at sea: where is all the plastic? Science 304:838

Vaughan R, Turner SD, Rose NL (2017) Microplastics in the sediments of a UK urban lake. Environ Pollut 229:10-18

Wagner M, Scherer C, Alvarez-Muñoz D, Brennholt N, Bourrain X, Buchinger S, Fries E, Grosbois C, Klasmeier J, Marti T, Rodriguez-Mozaz S, Urbatzka R, Vethaak AD, Winther-Nielsen M, Reifferscheid G (2014) Microplastics in freshwater ecosystems: what we know and what we need to know. Environ Sci Eur 26:12
Wesch C, Elert AM, Wörner M, Braun U, Klein R, Paulus M (2017) Assuring quality in microplastic monitoring: about the value of clean-air devices as essentials for verified data. Sci Rep 7:5424

Willis KA, Eriksen R, Wilcox C, Hardesty BD (2017) Microplastic distribution at different sediment depths in an urban estuary. Front Mar Sci 4:419

Woodall LC, Sanchez-Vidal A, Canals M, Paterson GLJ, Coppock R, Sleight V, Calafat A, Rogers AD, Narayanaswamy BE, Thompson RC (2014) The deep sea is a major sink for microplastic debris. R Soc Open Sci 1:140317

Woodall LC, Gwinnett C, Packer M, Thompson RC, Robinson LF, Paterson GL (2015) Using a forensic science approach to minimize environmental contamination and to identify microfibres in marine sediments. Mar Pollut Bull 95:40-46

Zalasiewicz J, Waters CN, do Sul JAI, Corcoran PL, Barnosky $\mathrm{AD}$, Cearreta A, Edgeworth M, Gałuszka A, Jeandel C, Leinfelder R (2016) The geological cycle of plastics and their use as a stratigraphic indicator of the Anthropocene. Anthropocene 13:4-17

Zbyszewski M, Corcoran PL (2011) Distribution and degradation of fresh water plastic particles along the beaches of Lake Huron, Canada. Water Air Soil Pollut 220:365-372

Zhang K, Su J, Xiong X, Wu X, Wu C, Liu J (2016) Microplastic pollution of lakeshore sediments from remote lakes in Tibet plateau, China. Environ Pollut 219:450-455

Zubris KAV, Richards BK (2005) Synthetic fibers as an indicator of land application of sludge. Environ Pollut 138:201-211

Publisher's Note Springer Nature remains neutral with regard to jurisdictional claims in published maps and institutional affiliations. 